\title{
Relationship between primary tumor FDG uptake and extensional or metastatic potential in patients with small cell lung cancer
}

\author{
Huynh Quang Huy
}

*Correspondence: huyhq@pnt.edu.vn

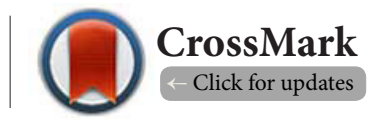

Radiology Department, Pham Ngoc Thach University of Medicine, Vietnam.

\begin{abstract}
Objective: To explore the maximum standardized uptake value (SUVmax) of primary tumors, as well as the relationship between SUVmax with tumor size, with tumor stage or with lymph nodal metastasis in small cell lung cancer (SCLC) patients who underwent 18F-fluorodeoxyglucose positron emission tomography-computed tomography (18F-FDG PETCT) for staging before initial treatment.

Methods: Thirty-two patients with SCLC who underwent 18F-FDG PET-CT scans before treatment were included in this study. Primary tumor SUVmax was calculated, and clinical stage, presence of local extension, as well as nodal and distant organ metastases were recorded. The patients were divided into low and high SUVmax groups by using the median SUVmax. The low SUVmax group consisted of 16 patients with $S U V \max <8.41$, while the high SUVmax group consisted of 16 patients with SUVmax $\geq 8.41$. The data from the two groups were compared for statistical differences.This study was approved by the Institute Research Medical Ethics Committee of Bach Mai hospital.

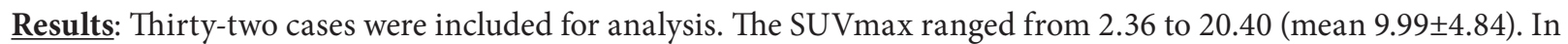
the low SUV group, 3 patients had local extension, 1 had nodal metastasis, and 13 haddistant organ metastasis. In the high SUV group, 5 patients had local extension, 12 had nodal metastasis, and 11 had distant organ metastases. There were nosignificant differences in local extension $(\mathrm{P}>0.05)$, distant organmetastasis $(\mathrm{P}>0.05)$, or in nodal metastasis rate $(\mathrm{P}>0.05)$ between the low SUV versus high SUV groups. In addition, there was a moderate correlation between SUVmax and tumor size $(r=0.504, P=0.003)$, SUVmax and tumor stage $(r=0.432, P=0.014)$, but not SUVmax and node stage $(r=-$ $0.195, \mathrm{P}=0.284)$ or SUVmaxand overall stage $(\mathrm{r}=-0.317, \mathrm{P}=0.077)$.

Conclusion: SUVmax was associated with tumor size, but not with distant metastases or lymph node involvement in patients with small cell lung cancer. Thus, SUVmax determined by 18F-FDGPET-CT is not predictive of the presence of metastases.
\end{abstract}

Keywords: 18F-FDG PET-CT, SUVmax, tumor stage, lymph nodal, small cell lung cancer (SCLC)

\section{Introduction}

Lung cancer is among the most common tumor types, representing $13 \%$ of newly diagnosed cancers worldwide. Both the absolute and relative frequencies of lung cancer have risen dramatically. Unfortunately, it remains by far the leading cause of cancer-related deaths, accounting for $18 \%$ of the total number of deaths [1]. Small cell lung cancer (SCLC), accounting for $10 \%$ of clinical lung cancer cases, is an aggressive malignancy strongly associated with smoking. It displays a distinct natural history characterized by a high growth fraction, rapid doubling time and early establishment of widespread metastatic lesions [2].

In patients with SCLC, it is important to determine whether the cancer is at alimited stage (LS) or extensive stage (ES).
LS cancers, which are potentially curable, are treated with chemotherapy and radiation, with surgical resection reserved for selected patients with stage I disease. ES cancers are incurable; systemic chemotherapy is used to improve quality of life and prolong survival [3].

Until 2011, the National Comprehensive Cancer Network (NCCN) recommended a $(99 \mathrm{~m}) \mathrm{Tc}-\mathrm{MDP}$ bone scan as part of the initial evaluation of all newly diagnosed SCLC patients. However, in 2012, the NCCN began recommending $18 \mathrm{~F}$ fluorodeoxyglucose positron emission tomography-computed tomography (18F-FDG PET-CT) in lieu of bone scan in its initial workup algorithm. PET has emerged in the last decade as an important tool in the staging and delineation of disease 
for conformal radiotherapy planning of non-SCLC. In 2009, Medicare approved the use of PET for the initial staging of SCLC. It is believed that PET may more accurately detect patients with ES disease than CT-staging alone. This stage migration allows physicians to withhold potentially toxic radiation therapy from poorer prognosis ES patients who would not benefit from it. With better ability to identify patients who will likely respond to treatment, stage-specific survival will improve [4].

Indeed, 18F-FDG PET-CT provides morphological and metabolic data of malignancy, and has become an important noninvasive tool for staging as well as assessment of the primary tumor and distant metastases in lung cancer. FDG uptake in the primary tumor is measured as the maximum standardized uptake value (SUVmax) by PET. SUVmax indicates the disease activity or the aggressiveness of tumor, can be easily obtained, and is the most widely used parameter for the analysis of $18 \mathrm{~F}$ FDG PET images in clinical practice. Metastasis occurs primarily by dissemination not only through the lymphatic and blood vessels but via local extension in SCLC. However, to date, few studies have evaluated the relationship between the primary tumor SUVmax and extensional or metastatic potentialin patients with SCLC.

In this study, we aim to explore the SUVmax of the primary tumor, as well as the relationship of SUVmax with tumor size, with tumor stage, and withand nodal or distant organ metastasisin SCLC patients who underwent 18F-FDG PET-CT for staging before initial treatment.

\section{Materials and Methods Clinical data}

We retrospectively analyzed the $18 \mathrm{~F}-\mathrm{FDG}$ PET-CT findings of 32 newly diagnosed SCLC patients with amean age of 61 years (range: 38-81 years), between December 2016 and October 2018. Patients were enrolled by convenient sampling method. There were 29 (90.6\%) males, and $3(9.4 \%)$ females.All patients were defined by histological or cytological evidence. The patients were referred to Bach Mai Nuclear Medicine and Oncology Center for initial staging with PET-CT scan before treatment. Histological diagnosis of the tumors was based on the criteria of the 2015 World Health Organization [5], and the tumor-node-metastasis (TNM) stage was determined according to the 8th Lung Cancer TNM classification by the International Association for the Study of Lung Cancer.This study was approved by the Institute Research Medical Ethics Committee of Bach Mai hospital.

\section{FDG PET-CT imaging}

18F-FDG PET-CT scans were performed with awhole-body PET-CT scanner. All patients had been fasting for at least 6 hours before PET imaging, and serum glucose levels were measured to ensure that the results were $180 \mathrm{mg} / \mathrm{dl}$. All patients had a glucose level below $180 \mathrm{mg} / \mathrm{dl}$ and were injected intravenously with $0.15-0.20 \mathrm{mCi} / \mathrm{kg}$ (7-12mCi) FDG. At 45
$60 \mathrm{~min}$ after the injection, data were acquired from the vertex to the upper thigh. Immediately after CT, a PET scan (PET-CT Biograph True Point, Siemens, Germany) was performed for approximately $25 \mathrm{~min}$, with 7 to 8 bed positions and $3 \mathrm{~min} /$ position. PET images were reconstructed iteratively with $\mathrm{CT}$ data for attenuation correction, using an inline integrated Siemens Esoft Workstation system (Germany). CT-integrated PET fusion images in transaxial, sagittal, and coronal planes were evaluated visually, and the SUVmax of lesions was obtained from transaxial images.

\section{Imaging analysis}

The PET-CT images were reviewed using the automatic PET-CT fusion software on the workstation. A volumetric region-ofinterest (ROI) around the outline of primary tumor in the SCLC was placed on the axial PET images using the semi-automatic software. A threshold of $40 \%$ of the maximum signal intensity was selected to delineate ROI. Then, SUVmax, SUVmean and tumor volume (TV) were automatically calculated by the PET-CT fusion software and these values were recordedfrom the workstation. Both radiologists who conducted the measurements together were blinded to the clinical details.

\section{Statistical analysis}

Statistical analysis was done using SPSS 22.0 (Chicago, Illinois, USA). The mean of the measurement data was expressed as mean \pm standard deviation (mean \pm S.D.). The differences of tumor SUVmax in independent groups were compared using independent $t$ test. An evaluation was made of the linear relationship between tumor size, tumor stage, nodal stage, and overall stages of the patients and their SUVmaxusing Spearman's correlation. P-values less than 0.05 were considered significant.

\section{Results}

The SUVmax ranged from 2.36 to 20.40 (mean $9.99 \pm 4.84$ ). The median SUVmax was 8.41, the low SUVmax group ranged from 2.36 to 8.32 (mean of $6.19 \pm 1.93$ ), and the high SUVmax group ranged from 8.49 to 20.40 (mean of $13.80 \pm 3.72$ ). The clinical characteristics of patients in the low and high groups are shown in Table 1.

Local extension, lymph node, and distant organ metastasis in the low and high group are shown in Table 2. Local extension (including primary tumor invasion to the main bronchus, visceral pleura, chest wall, mediastinum, and recurrent laryngeal nerve) were seen in 3 patients (18.8\%) in the low SUVmax group and 5 patients $(31.2 \%)$ in the high SUVmax group ( $P>0.05$ between the groups). Lymph node and distant organ metastases were not different in the low SUVmax $(68.8 \%, 11 / 16 ; 81.2 \%, 13 / 16)$ compared to those of the high SUVmax group $(75.0 \%, 12 / 16$; $68.8 \%, 11 / 16)(P>0.05$ between the groups).

In addition, Spearman's rank correlation showed a significant association of SUVmax ofprimary tumor with tumor size, tumor stage, nodal stage, and overall stage of the patients (Table 3). 
Table 1. Clinical Characteristics of Patients $(n=32)$.

\begin{tabular}{|c|c|c|}
\hline \multirow[t]{2}{*}{ Characteristics } & \multicolumn{2}{|c|}{ No. of patients and percentage } \\
\hline & $\begin{array}{l}\text { Low SUVmax group } \\
\text { (SUVmax }<8.41), \\
(n=16)\end{array}$ & $\begin{array}{l}\text { High SUVmax group } \\
\text { (SUVmax } \geq 8.41) \\
(\mathrm{n}=16)\end{array}$ \\
\hline \multicolumn{3}{|l|}{ Age (38-81 years) } \\
\hline$<59$ years & $8(50 \%)$ & $4(25 \%)$ \\
\hline$\geq 59$ years & $8(50 \%)$ & $12(75 \%)$ \\
\hline \multicolumn{3}{|l|}{ Sex } \\
\hline Male & $13(81.2 \%)$ & $16(100 \%)$ \\
\hline Female & $3(18.8 \%)$ & $0(0 \%)$ \\
\hline \multicolumn{3}{|l|}{ Tumor location } \\
\hline Left upper lobe & $6(37.5 \%)$ & $7(43.75 \%)$ \\
\hline Left lower lobe & $1(6.25 \%)$ & $0(0 \%)$ \\
\hline Right upper lobe & $5(31.25 \%)$ & $5(31.25 \%)$ \\
\hline Right middle lobe & $1(6.25 \%)$ & $2(12.5 \%)$ \\
\hline Right lower lobe & $3(18.75 \%)$ & $2(12.5 \%)$ \\
\hline \multicolumn{3}{|l|}{ TNM stage } \\
\hline $\mathrm{I}$ & $0(0 \%)$ & $1(6.2 \%)$ \\
\hline II & $1(6.2 \%)$ & $1(6.2 \%)$ \\
\hline III & $3(18.8 \%)$ & $5(31.2 \%)$ \\
\hline IV & $12(75.0 \%)$ & $9(56.2 \%)$ \\
\hline
\end{tabular}

Table 2. Summary of Local Extension, Lymph Node, and Distant Organ Metastases.

\begin{tabular}{|c|c|c|c|}
\hline & $\begin{array}{l}\text { Low SUVmax } \\
\text { group (SUVmax } \\
<8.41 \text { ) }\end{array}$ & $\begin{array}{l}\text { High SUVmax } \\
\text { group (SUVmax } \\
\geq 8.41 \text { ) }\end{array}$ & P-value \\
\hline Local extension (\%) & $3(18.8 \%)$ & $5(31.2 \%)$ & $>0.05$ \\
\hline $\begin{array}{l}\text { Lymph node } \\
\text { metastasis (\%) }\end{array}$ & $11(68.8 \%)$ & $12(75.0 \%)$ & $>0.05$ \\
\hline $\begin{array}{l}\text { Distant organ } \\
\text { metastasis (\%) }\end{array}$ & $13(81.2 \%)$ & $11(68.8 \%)$ & $>0.05$ \\
\hline
\end{tabular}

Table 3. Correlation of SUVmax and Tumor Size or Tumor Stage.

\begin{tabular}{lll}
\hline & Correlation coefficient & P-value \\
\hline Tumor diameter & 0.504 & 0.003 \\
Tumor stage & 0.432 & 0.014 \\
Node stage & -0.195 & 0.284 \\
Overall stage & -0.317 & 0.077 \\
\hline
\end{tabular}

Figures 1-4 are the PET-CT images of patient with SCLC at stage IV, according to the TNM classification.

\section{Discussion}

Although CT or magnetic resonance imaging (MRI) provides precise anatomical and morphological information, the role of FDG-PET-CT has increased for diagnosis and staging of lung cancer [6]. Recently, FDG uptake has been reported to be a prognostic factor in patients with lung cancer [6-8]. Patz et al. [9] demonstrated that patients with positive FDG-PET-CT results, after treatment for lung cancer, had a significantly worse

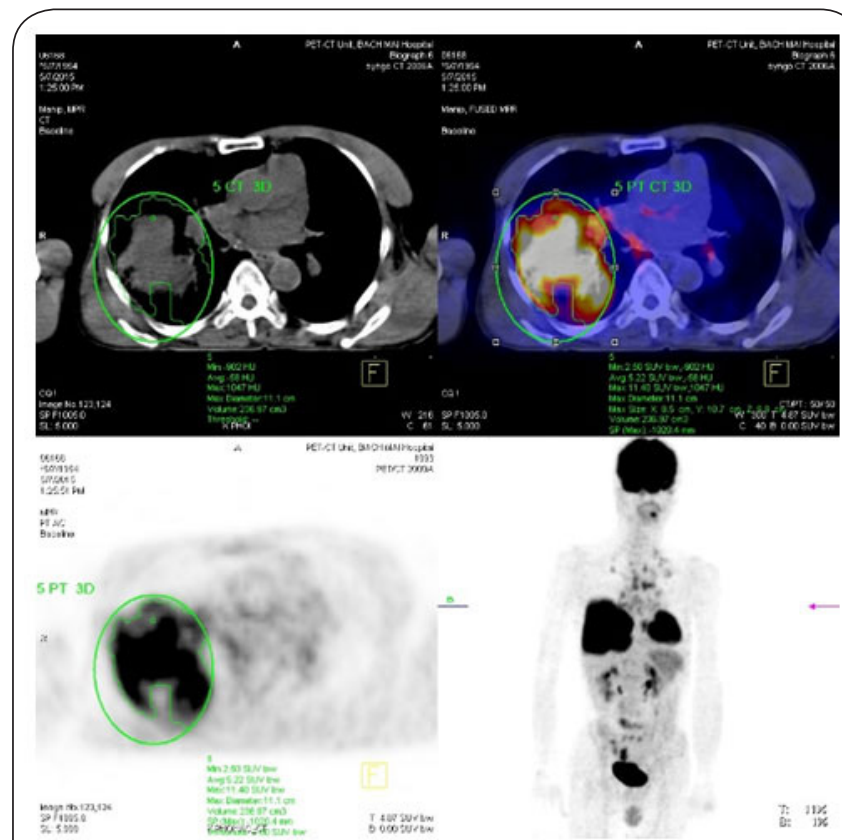

Figure 1. The primary tumor located at upper right lobe with tumor diameter was $11.1 \mathrm{~cm}$ and SUVmax was 11.40 .

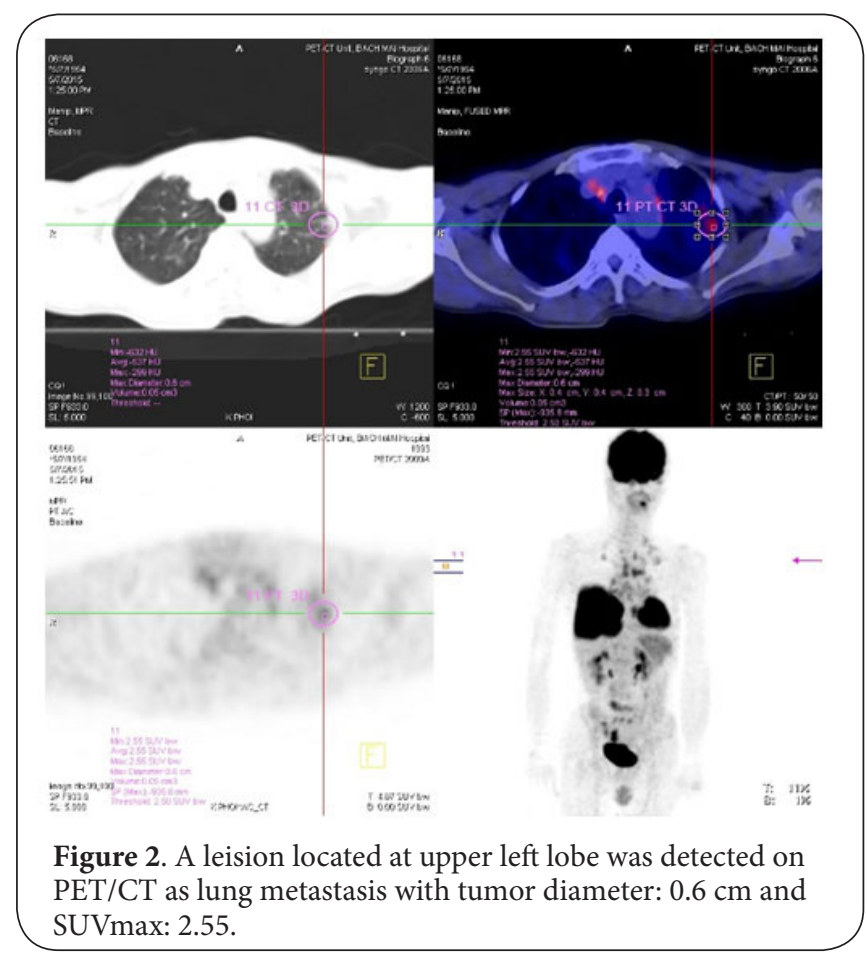

prognosis than patients with negative results. Therefore, we examined whether SUVmax correlates with tumor size, with lymph node, or with distant metastases in patients with SCLC.

We studied the value of SUVmax in patients diagnosed with SCLC. Median SUVmax value of the primary tumor of the total study population was 8.41 (range 2.36 to 20.40) and 

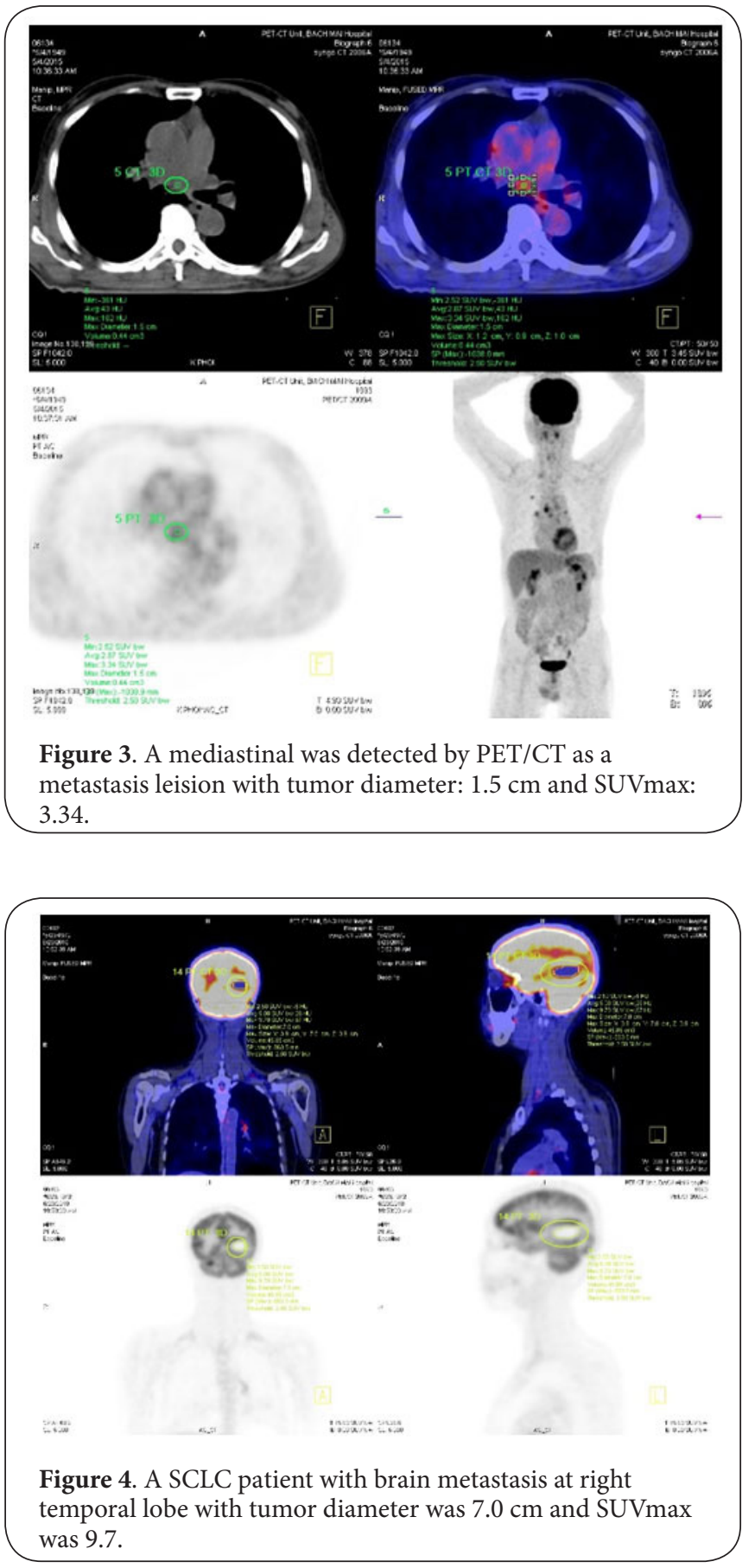

the mean was $9.99 \pm 4.84)$. Tumor size, but not lymph node or distant metastases, was found to be related to the tumor SUVmax in our study. Our data was different from the observations of van der Leest el al. [10] which studied in 75 chemonaive patientsand showed that median SUVmax value of the primary tumor of the total study population was 11.3 (range 1.18-25.99). And, SUVmax of the primary tumor was significantly higher in the patients with stage IV disease compared to stage I-III disease. This can be mainly explained that our population sample size was smaller and most of our patients at stage IV according to TNM classification.

The association between the SUVmax and tumor size could be useful in choosing the appropriate treatment such as chemotherapy or surgery. And, this result could help future researches with SUVmaxas a predict factor in patients with SCLC if there is any relationship between primary tumor SUVmax and survival time.

FDG PET-CT is an important adjunct examination in the evaluation of SCLC, combining functional information (FDG PET) with anatomic information (CT). FDG PET-CT is invaluable in clinical staging, restaging, guiding therapy, and suggesting prognosis. SCLC is readily identified by FDG PET because of the high metabolic activity of this cancer type. Some studies have reported improved staging accuracy with FDG PET compared with CT alone, and that FDG PET-CT is more accurate than FDG PET alone [10,16-18]. The use of FDG PET in ES-SCLC in $19 \%$ of patients and to down staging from ES-SCLC to LS-SCLC in $8 \%$ of patients. Although FDG PET is inferior to CT or MR imaging for the detection of brain metastases, it is more sensitive and specific than conventional imaging for detecting metastatic disease [19]. 18F-FDG PET-CT has been increasingly used for staging, treatment response assessment, and therapy planning in lung cancer since it was introduced into clinical practice in 1998 [20].

Apart from qualitative assessment in the detection of metastases, PET-CT provides the opportunity of a semi-quantitative measure of tumor glycolysis using SUV. SUVmax is the highest SUV measurement in the ROI and is the most commonly used measurement in clinical practice because it is least affected by partial volume effects [21]. SUVmax is also defined as a unique noninvasive method for studying biochemical and metastatic changes in cancer tissues [22]. The relationships between SUVmax of primary tumor with local extension, with lymph node, and with distant organ metastasis were investigated.

Our results showed that the increases of lymph nodes and of distant organ metastasis do not correlatewith increasing primary tumor SUVmax in SCLC patients. In addition, the results showed that local extension of the primary tumor (such as the main bronchus, visceral pleura, chest wall, or mediastinum) were not different in the high SUVmax group when compared to the low SUVmax group; these results had not yet been reported elsewhere.

SUVmax has been correlated with tumor proliferation rate, tumor grade, and expression of glucose transporters, which are biomarkers in various types of malignant tumors. Metastasis is the major cause of death due to several malignancies, including SCLC, and it occurs primarily by dissemination through the lymphatic and blood vessels. Nambu et al. (2009) have reported that the likelihood of lymph node metastasis increases with the increase of SUVmax of the primary tumor in patients with NSCLC [23]. Our results are different from their observations. In their study, they also noted that when the SUVmax of the primary tumor was greater than 12 , the probability of lymph 
node metastasis was high, reaching $70 \%$, irrespective of the degree of FDG accumulation into the lymph node stations. Thus, such results in NSCLC allow to more sensitively predict the presence of lymph node metastases, including microscopic ones that cannot be detected by direct evaluation of the lymph node stations. This difference between SCLC and NSCLC can be explained by the high growth fraction, rapid doubling time and early establishment of widespread metastatic lesions in SCLC than those in NSCLC. Most SCLC patients in our study were diagnosed at the stage IV according to TNM classification. Therefore, the SUVmax is not varied significantly by lymph node stagesand metastasis stages.

In patients with NSCLC, Zhu et al. [24] have shown that the average SUVmax was significantly lower in patients without any metastasis than in those with lymph node and/or distant organ metastasis. They suggested that SUVmax may, in part, reflect the potential of metastasis of the primary tumor in NSCLC. However, there was no upper threshold of SUVmax of NSCLC, above which lymph node and/or distant organ metastasis were always present. Thus, even when a primary tumor in NSCLC shows high SUVmax exceeding 10 or 20, the presence of lymph node and/or distant organ metastasis is still inconclusive, based on the evaluation of the SUVmax of the primary tumor.

The utility of PET in the initial staging of patients with SCLC has been evaluated in several studies comparing pre-treatment 18F-FDGPET to conventional staging procedures $[14,17,25-28]$ (Table 4). Study designs varied with regards to the extent of conventional staging, the use of PET alone or PET-CT, and the method used to define PET positivity. In addition, some studies required biopsies of all FDG-avid lesions that would alter stage, whereas others used clinical follow-up to confirm PET findings. Unfortunately, several studies did not validate PET findings and stage alterations by either method.

SCLC is a highly metabolic malignancy, leading to a sensitivity of $100 \%$ for PET detection of primary tumors. Overall, cumulative staging concordance was $84 \%$ between PET and conventional imaging, with better concordance noted in prospective (89\%, range $83-100 \%$ ) rather than retrospective (80\%, range 67-100\%) studies [29]. Of the 204 patients with LS-SCLC by conventional imaging, $19 \%$ were up-staged to ES by PET, with similar findings in the prospective $(17 \%$, range $0-33 \%)$ and retrospective (20\%, range $0-54 \%)$ studies. Of the 199 patients with ES-SCLC by conventional imaging, $11 \%$ were down-staged to LS by PET, with a much lower percentage of down-staged patients noted in the prospective $(5 \%$, range $0-11 \%)$ than retrospective (18\%, range $0-40 \%)$ studies. For metastatic sites, PET was superior to standard imaging in terms of both sensitivity and specificity. However, PET was inferior to MRI or CT for the detection of brain metastases [29].

There were some limitations in our study. Firstly, the sample size was relatively small. Particularly, there were only 3 cases without any metastasis (by 18F-FDG PET-CT). Further studies with larger patient groups are needed toassess the relationship between primary tumor SUVmaxand local extension, nodal or distant organ metastases inpatients with SCLC. Secondly, local extension, as well as nodaland distant organ metastases, were determined accordingto PET-CT, not the gold standard of pathological findings. Thus, the results need to be verified as afollow-up. Additionally, we conclude that the SUVmax of the primary tumor is correlated with tumor size. However, we do not recommend a potentially accurate method to correct the SUV for partial volume effects; these effectscan significantly lower the SUV when the tumor size isless than 2 to $3 \mathrm{~cm}$ [30]. Thus, further research should be carried out to explore the relationship ofcorrected SUV with tumor size.

\section{Conclusion}

In conclusion, we have shown that SUVmax is associated with tumor size, but not with distant metastases or lymph node involvement in patients with SCLC. This type of lung cancer is hight malignancy and rapid metastasis with most patients is presented at stage IV. Thus, SUVmax determined by FDGPET-CT is not predictive of the presence of metastases at

Table 4. PET for initial staging of SCLC.

\begin{tabular}{|c|c|c|c|c|c|c|}
\hline \multirow[t]{2}{*}{ Trial } & \multirow[t]{2}{*}{$\mathbf{N}$} & \multirow[t]{2}{*}{ Stage concordance (\%) } & \multicolumn{2}{|l|}{ LS } & \multicolumn{2}{|l|}{ ES } \\
\hline & & & $\mathbf{N}$ & Up-staged $(\mathrm{LS} \rightarrow \mathrm{ES})(\%)$ & $\mathbf{N}$ & Down-staged $(\mathrm{ES} \rightarrow \mathrm{LS})(\%)$ \\
\hline \multicolumn{7}{|l|}{ Prospective } \\
\hline Chin [18] & 18 & 38 & 9 & 22 & 9 & 11 \\
\hline Bradley [12] & 24 & 88 & 24 & 88 & 0 & - \\
\hline Brink [19] & 120 & 88 & 51 & 20 & 69 & 4 \\
\hline Kut [13] & 18 & 100 & 6 & 0 & 12 & 0 \\
\hline Fisher [15] & 29 & 83 & 9 & 33 & 20 & 5 \\
\hline \multicolumn{7}{|l|}{ Retrospective } \\
\hline Haubner [25] & 7 & 100 & 6 & 0 & 1 & 0 \\
\hline Schumacher [27] & 26 & 73 & 13 & 54 & 13 & 0 \\
\hline Shen $[28]$ & 25 & 92 & 10 & 10 & 15 & 7 \\
\hline Blum [17] & 15 & 67 & 15 & 33 & 0 & - \\
\hline Azad [14] & 46 & 74 & 26 & 15 & 20 & 40 \\
\hline
\end{tabular}


Huynh Quang Huy, Medical Imaging and Radiology 2019,

http://www.hoajonline.com/journals/pdf/2054-1945-7-1.pdf

doi: 10.7243/2054-1945-7-1

advanced stage. Larger prospective and randomized analyses may potentially reveal more significant relationships.

\section{List of abbreviation}

FDG: fluorodeoxyglucose

SUVmax: maximum standardized uptake value

SCLC: small cell lung cancer

18F-FDG PET-CT: 18F-fluorodeoxyglucose positron emission

tomography-computed tomography

LS:limited stage

ES: extensive stage

TNM: tumor-node-metastasis

\section{Competing interests}

The author declares that he has no competing interests.

\section{Acknowledgment}

I would like to thank physicians, administrative staff at Nuclear Medicine and Oncology Center of Bach Mai Hospital and Radiology Department of Pham Ngoc Thach University of Medicine for allowing me to undertake this research.

\section{Publication history}

Senior Editor: Domenico Rubello, Santa Maria della Misericordia Hospital, Italy.

Received: 18-Nov-2018 Final Revised: 22-Dec-2018

Accepted: 24-Dec-2018 Published: 18-Jan-2019

\section{References}

1. Jemal A, Bray F, Center MM, Ferlay J, Ward E and Forman D. Global cancer statistics. CA Cancer J Clin. 2011; 61:69-90. I Article I PubMed

2. Gustafsson BI, Kidd M, Chan A, Malfertheiner MV and Modlin IM. Bronchopulmonary neuroendocrine tumors. Cancer. 2008; 113:5-21. I Article I PubMed

3. Kalemkerian GP and Schneider BJ. Advances in Small Cell Lung Cancer. Hematol Oncol Clin North Am. 2017; 31:143-156. | Article I PubMed

4. Feinstein AR, Sosin DM and Wells CK. The Will Rogers phenomenon. Stage migration and new diagnostic techniques as a source of misleading statistics for survival in cancer. N Engl J Med. 1985; 312:1604-8. | Article | PubMed

5. Travis WD, Brambilla E, Nicholson AG, Yatabe Y, Austin JHM, Beasley MB, Chirieac LR, Dacic S, Duhig E, Flieder DB, Geisinger K, Hirsch FR, Ishikawa Y, Kerr KM, Noguchi M, Pelosi G, Powell CA, Tsao MS and Wistuba I. The $\mathbf{2 0 1 5}$ World Health Organization Classification of Lung Tumors: Impact of Genetic, Clinical and Radiologic Advances Since the 2004 Classification. J Thorac Oncol. 2015; 10:1243-1260. | Article | PubMed

6. Al-Sarraf N, Gately K, Lucey J, Aziz R, Doddakula K, Wilson L, McGovern $E$ and Young V. Clinical implication and prognostic significance of standardised uptake value of primary non-small cell lung cancer on positron emission tomography: analysis of 176 cases. Eur J Cardiothorac Surg. 2008; 34:892-7. | Article | PubMed

7. Dhital K, Saunders CA, Seed PT, O’Doherty MJ and Dussek J. [(18)F] Fluorodeoxyglucose positron emission tomography and its prognostic value in lung cancer. Eur J Cardiothorac Surg. 2000; 18:425-8. | PubMed

8. Hanin FX, Lonneux M, Cornet J, Noirhomme P, Coulon C, Distexhe J and Poncelet AJ. Prognostic value of FDG uptake in early stage non-small cell lung cancer. Eur J Cardiothorac Surg. 2008; 33:819-23. | Article | PubMed

9. Patz EF, Jr., Connolly J and Herndon J. Prognostic value of thoracic FDG PET imaging after treatment for non-small cell lung cancer. AJR Am J Roentgenol. 2000; 174:769-74. | Article | PubMed
10. van der Leest C, Smit EF, Baas J, Versteijlen RJ, van Walree N, Hoogsteden $\mathrm{HC}$ and Aerts JG. SUVmax during 18FDG-PET scanning in small cell lung cancer: similar information as in non-small cell lung cancer? Lung Cancer. 2012; 76:67-71. | Article I PubMed

11. Podoloff DA, Ball DW, Ben-Josef E, Benson AB, 3rd, Cohen SJ, Coleman RE, Delbeke D, Ho M, Ilson DH, Kalemkerian GP, Lee RJ, Loeffler JS, Macapinlac HA, Morgan RJ, Jr., Siegel BA, Singhal S, Tyler DS and Wong RJ. NCCN task force: clinical utility of PET in a variety of tumor types. $J$ Natl Compr Canc Netw. 2009; 7 Suppl 2:S1-26. | PubMed

12. Bradley JD, Dehdashti F, Mintun MA, Govindan R, Trinkaus K and Siegel BA. Positron emission tomography in limited-stage small-cell lung cancer: a prospective study. J Clin Oncol. 2004; 22:3248-54. | Article | PubMed

13. Kut V, Spies W, Spies S, Gooding W and Argiris A. Staging and monitoring of small cell lung cancer using [18F]fluoro-2-deoxy-D-glucose-positron emission tomography (FDG-PET). Am J Clin Oncol. 2007; 30:45-50. | Article I PubMed

14. Azad A, Chionh F, Scott AM, Lee ST, Berlangieri SU, White S and Mitchell PL. High impact of 18F-FDG-PET on management and prognostic stratification of newly diagnosed small cell lung cancer. Mol Imaging Biol. 2010; 12:443-51. | Article | PubMed

15. Fischer BM, Mortensen J, Langer SW, Loft A, Berthelsen AK, Petersen $\mathrm{BI}$, Daugaard G, Lassen $\mathrm{U}$ and Hansen $\mathrm{HH}$. A prospective study of PET/ CT in initial staging of small-cell lung cancer: comparison with $\mathrm{CT}$, bone scintigraphy and bone marrow analysis. Ann Oncol. 2007; 18:338-45. | Article I PubMed

16. Al-Jahdali H, Khan AN, Loutfi S and Al-Harbi AS. Guidelines for the role of FDG-PET/CT in lung cancer management. J Infect Public Health. 2012; 5 Suppl 1:S35-40. | Article | PubMed

17. Blum R, MacManus MP, Rischin D, Michael M, Ball D and Hicks RJ. Impact of positron emission tomography on the management of patients with small-cell lung cancer: preliminary experience. Am J Clin Oncol. 2004; 27:164-71. | Article | PubMed

18. Chin R, Jr., McCain TW, Miller AA, Dunagan DP, Acostamadiedo J, Douglas Case L, Harkness BA, Adler LP and Haponik EF. Whole body FDG-PET for the evaluation and staging of small cell lung cancer: a preliminary study. Lung Cancer. 2002; 37:1-6. | Article | PubMed

19. Brink I, Schumacher T, Mix M, Ruhland S, Stoelben E, Digel W, Henke M, Ghanem N, Moser E and Nitzsche EU. Impact of [18F]FDG-PET on the primary staging of small-cell lung cancer. Eur J Nucl Med Mol Imaging. 2004; 31:1614-20. | Article | PubMed

20. De Wever W, Ceyssens S, Mortelmans L, Stroobants S, Marchal G, Bogaert J and Verschakelen JA. Additional value of PET-CT in the staging of lung cancer: comparison with CT alone, PET alone and visual correlation of PET and CT. Eur Radiol. 2007; 17:23-32. | Article | PubMed

21. Ikushima H, Dong L, Erasmus J, Allen P, McAleer MF, Zhuang Y, Sasaki R and Komaki R. Predictive value of 18F-fluorodeoxyglucose uptake by positron emission tomography for non-small cell lung cancer patients treated with radical radiotherapy. J Radiat Res. 2010; 51:465-71. | Article I PubMed

22. Gambhir SS. Molecular imaging of cancer with positron emission tomography. Nat Rev Cancer. 2002; 2:683-93. | Article | PubMed

23. Nambu A, Kato S, Sato Y, Okuwaki H, Nishikawa K, Saito A, Matsumoto K, Ichikawa T and Araki T. Relationship between maximum standardized uptake value (SUVmax) of lung cancer and lymph node metastasis on FDG-PET. Ann Nucl Med. 2009; 23:269-75. | Article | PubMed

24. Zhu SH, Zhang Y, Yu YH, Fu Z, Kong L, Han DL, Fu L, Yu JM and Li J. FDG PET-CT in non-small cell lung cancer: relationship between primary tumor FDG uptake and extensional or metastatic potential. Asian Pac J Cancer Prev. 2013; 14:2925-9. | Article I PubMed

25. Hauber HP, Bohuslavizki KH, Lund CH, Fritscher-Ravens A, Meyer A and Pforte A. Positron emission tomography in the staging of small-cell lung cancer : a preliminary study. Chest. 2001; 119:950-4. | Article | PubMed

26. Kamel EM, Zwahlen D, Wyss MT, Stumpe KD, von Schulthess GK and Steinert HC. Whole-body (18)F-FDG PET improves the management of patients with small cell lung cancer. J Nucl Med. 2003; 44:1911-7. | Article I PubMed 
Huynh Quang Huy, Medical Imaging and Radiology 2019,

http://www.hoajonline.com/journals/pdf/2054-1945-7-1.pdf

27. Schumacher T, Brink I, Mix M, Reinhardt M, Herget G, Digel W, Henke M, Moser $E$ and Nitzsche E. FDG-PET imaging for the staging and follow-up of small cell lung cancer. Eur J Nucl Med. 2001; 28:483-8. | PubMed

28. Shen YY, Shiau YC, Wang JJ, Ho ST and Kao CH. Whole-body 18F-2deoxyglucose positron emission tomography in primary staging small cell lung cancer. Anticancer Res. 2002; 22:1257-64. | PubMed

29. Kalemkerian GP. Staging and imaging of small cell lung cancer. Cancer Imaging. 2012; 11:253-8. | Article | PubMed Abstract | PubMed FullText

30. Vesselle H, Freeman JD, Wiens L, Stern J, Nguyen HQ, Hawes SE, Bastian $P$, Salskov A, Vallieres $E$ and Wood DE. Fluorodeoxyglucose uptake of primary non-small cell lung cancer at positron emission tomography: new contrary data on prognostic role. Clin Cancer Res. 2007; 13:325563. | Article | PubMed

\section{Citation:}

Huy HQ. Relationship between primary tumor FDG uptake and extensional or metastatic potential in patients with small cell lung cancer. Med Imaging Radiol. 2018; 7:1.

http://dx.doi.org/10.7243/2054-1945-7-1 